\title{
Discrete Gene Loci Regulate Neurodegeneration, Lymphocyte Infiltration, and Major Histocompatibility Complex Class II Expression in the CNS
}

\author{
Olle Lidman, ${ }^{1}$ Maria Swanberg, ${ }^{1}$ Linn Horvath, ${ }^{2}$ Karl W. Broman, ${ }^{3}$ Tomas Olsson, ${ }^{1 *}$ and Fredrik Piehl ${ }^{1 *}$ \\ Departments of ${ }^{1}$ Clinical Neuroscience, Neuroimmunology Unit and ${ }^{2}$ Medicine, Rheumatology Research Unit, Karolinska Institute, Karolinska Hospital, \\ S-17176, Stockholm, Sweden, and 32Department of Biostatistics, Johns Hopkins University, Baltimore, Maryland 21205
}

\begin{abstract}
Neurodegeneration and inflammation are fundamental aspects of many neurological diseases. A genome-wide scan of the response to ventral root avulsion (VRA) in a rat F2 cross discloses specific gene regions that regulate these processes. Two gene loci displayed linkage to neurodegeneration and T cell infiltration, respectively, and a single locus displayed extreme linkage to VRA-induced major histocompatibility complex class II expression on microglia. The demonstration that polymorphic genes in different loci control neurodegeneration and CNS inflammation has implications for various experimental rodent nervous system paradigms and potentially for genetically regulated susceptibility to a variety of human CNS diseases.
\end{abstract}

Key words: axotomy; motoneuron; degeneration; immunity; microglia; mapping

\section{Introduction}

Numerous CNS diseases of both inflammatory and primarily noninflammatory origin contain elements of inflammation, with $\mathrm{T}$ cell infiltration, major histocompatibility complex (MHC) class II expression, and neuron-axon damage (Itagaki et al., 1988; McGeer et al., 1988; Kawamata et al., 1992; Engelhardt et al., 1993; Trapp et al., 1998; Kil et al., 1999; Togo et al., 2002) (for review, see Gonzalez-Scarano and Baltuch, 1999; Neumann et al., 2002; Wyss-Coray and Mucke, 2002). Their complex etiology often includes a genetic predisposition (Tanzi and Bertram, 2001). If the disease predisposing genes could be exactly defined, they would constitute prime targets for new therapy or disclose pathogenetic pathways that could be targeted. Most genes instrumental in these complex disorders are likely to modestly affect risks, be evolutionary conserved in the population, and vary between individuals. With the exception of apolipoprotein $\mathrm{E}$ (Strittmatter et al., 1993), gene mappings by linkage analysis in human family materials have in most cases failed to unravel discrete genes (Cleveland and Rothstein, 2001; DeStefano et al., 2001; Scott et al., 2001; Hicks et al., 2002; Myers et al., 2002). In contrast, the use of intercrosses of inbred rodent strains being susceptible or resistant for particular phenotypes can identify

Received July 21, 2003; revised Sept. 2, 2003; accepted Sept. 3, 2003.

This work was supported by grants from the Wadsworth Foundation, Torsten and Ragnar Söderbergs Foundation, Björklunds Foundation, Nils and Bibbi Jenssens Foundation, the Swedish Foundation for Neurologically Disabled, Montel Williams Foundation, and the Swedish Research Council. We thank Britt Dahlgren, Ingrid Dahlman, and Ellen lacobaeus for genotyping work, Anna Glaser, Holger Luthman, and Erik Wallström for expert advice in genetics, and Staffan Cullheim for comments on this manuscript.

${ }^{*}$ T.O. and F.P. contributed equally to this work.

Correspondence should be addressed to Olle Lidman, Neuroimmunology Unit, Department of Clinical Neuroscience, Karolinska Institute, CMM, L8:04, Karolinska Hospital, S-17176, Stockholm, Sweden. E-mail: Olle.Lidman@cmm.ki.se.

Copyright $\odot 2003$ Society for Neuroscience $\quad$ 0270-6474/03/239817-07\$15.00/0 gene regions (Griffiths et al., 1999) and also position diseaseassociated genes (McIntire et al., 2001; Olofsson et al., 2003). To study the gene control of neurodegeneration and CNS inflammation, we have selected an as simple and reproducible rodent model as possible, ventral root avulsion (VRA) in the adult rat (Koliatsos et al., 1994; Piehl et al., 1999; Lundberg et al., 2001; Hu et al., 2002) (see Fig. 1). VRA results in a very proximal axotomy of motor axons at the boundary of the central and peripheral nervous systems and a substantial loss of axotomized cells during the second and third postoperative weeks. Lesioned motoneurons deprived of any physical contact with peripheral nerve tissue, thus, degenerate in a similar manner as many other CNS nerve cell populations (Lieberman, 1971).

The cellular responses to axonal lesions, collectively termed the axon reaction (Lieberman, 1971), comprise changes in lesioned nerve cells and activation of surrounding glia. Since its first description at the end of the nineteenth century (Nissl, 1892), the axon reaction has been intensely investigated to reveal crucial mechanisms, especially such that lead to the death of damaged cells and regulate the activation of CNS resident glial cells. The glial cell activation may be important for the interaction with the immune system through the expression of immune-related molecules such as MHC antigens (Kreutzberg et al., 1989; Maehlen et al., 1989; Olsson et al., 1989). To date a plethora of different candidate gene products possibly involved in the regulation of nerve injury-induced responses have been identified. In most cases the notion of involvement of a certain gene is based on studies of expression pattern, gene knock-out or in vivo neutralization/stimulation. However, because axotomy-induced inflammation and nerve cell death are likely to be determined by several interconnected events that depend on many different genes, the chances of identifying key events using classical hy- 
pothesis driven research and purely mechanistic approaches are limited.

We here selected rat strains with differences in degree of neuronal loss, recruitment of T cells, glial activation, and $\mathrm{MHC}$ class II expression after VRA, for a genetic dissection in a F2 population established by intercrossing DA and PVG strains. This revealed four quantitative trait loci (QTLs) with regulatory effects on different aspects of the VRA response. Exact positioning of the responsible genes in these QTLs can identify crucial steps in the regulation of CNS inflammation and neurodegeneration in response to insults of primarily noninflammatory origin.

\section{Materials and Methods}

Animals and breeding. The $\mathrm{DA}\left(\mathrm{RT}^{\mathrm{avl}}\right)$ strain was originally generously provided by Professor Hans Hedrich (Medizinische Hochschule, Hannover, Germany), whereas the PVG(RT1 $\left.{ }^{c}\right)$ strain was obtained from Harlan UK Ltd. (Blackthorn, UK). The rats used for experiments were bred at our in-house breeding facility under specific pathogen-free and climatecontrolled conditions with $12 \mathrm{hr}$ light/dark cycles, housed in polystyrene cages containing wood shavings, and fed standard rodent chow and water ad libitum. The intercross experiment was performed reciprocally, with $\mathrm{F} 2$ progeny originating from both female DA and PVG founders; $95 \mathrm{~F} 2(\mathrm{DA} \times \mathrm{PVG})$ and $91 \mathrm{~F} 2(\mathrm{PVG} \times \mathrm{DA})$. Both female and male rats were studied, and the total number of analyzed animals in each group was 18 DA, 18 PVG, 24 F1, and 186 F2.

Nerve lesion. All animals were subjected to unilateral avulsion of the left L3-L5 ventral roots under standardized conditions and in deep isoflurane anesthesia at an age of 6-8 weeks with a postoperative survival time of $14 \mathrm{~d}$. Animals were killed with $\mathrm{CO}_{2}$ and per-

fused with cold PBS. Spinal cords were carefully examined in a dissection microscope to verify the completeness of the lesion and to exclude signs of hemorrhage, necrotic zones, or direct damage to the cord. Six animals were excluded from further analysis. Serial transverse frozen sections (14 $\mu \mathrm{m})$ of tissue from the L4 segment of the spinal cord were cut with a cryostat. All experiments in this study were approved by the local ethical committee for animal experimentation (Stockholms Norra Djurförsöksetiska Nämnd).

Cell counts. Nerve cell counts of cresyl violet counterstained sections were performed as described previously (Lundberg et al., 2001). In brief, counts were performed blindly by an observer on every fifth section with a total of 15 sections from each rat. Motoneuron cell sizes in the counted population was assessed by measuring the soma area at high magnification in parental rats $(n>120$ contralateral cells and $n>70$ axotomized cells, respectively, for each sex and strain combination). The mean soma size in axotomized cells was highly similar (72-73\%) compared with unlesioned cells on the contralateral side in all groups. The mean soma diameter of unlesioned and axotomized cells in the measured material was used to calculate a correction factor for cell counts according to the Abercrombie formula (Guillery and Herrup, 1997) that subsequently was applied to the entire population. The degree of neurodegeneration is presented as a ratio of the total number of motoneurons on lesioned and unlesioned sides, respectively, in each rat. The method may be less sensitive to differences in absolute cell numbers between strains than stereological techniques (Guillery and Herrup, 1997), but the primary objective has been b

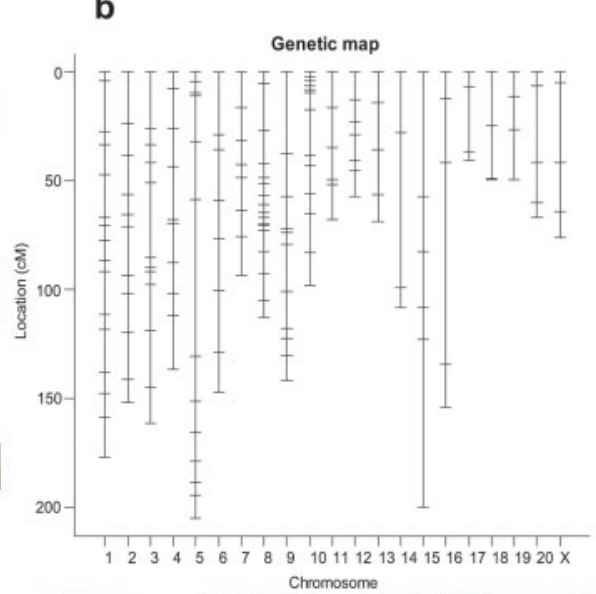

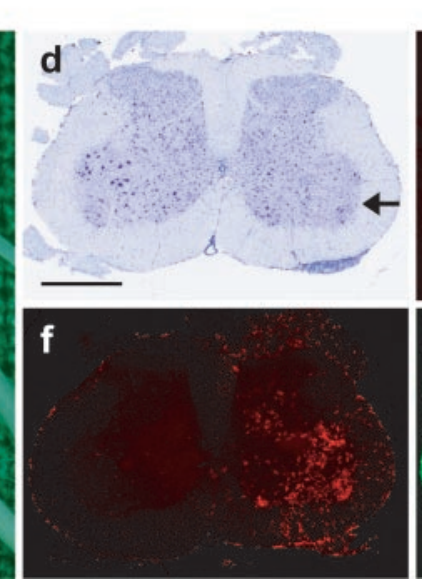

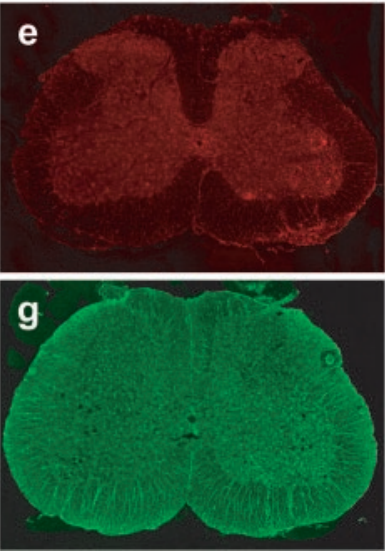

to establish the relative reduction in the number of cells between the lesioned and contralateral sides in individual animals.

Immunohistochemistry and image analysis. The protocol for immunohistochemistry has been described in detail previously (Hammarberg et al., 2000). The following antisera were used: anti-rat Ia antigen (MHC class II; clone OX-6, mouse IgG1; Serotec, Oxford, UK), anti-rat CD3 $\epsilon$ (Santa Cruz Biotechnology, Santa Cruz, CA), anti-rat NKR-P1 (clone 3.2.3, mouse IgG1; Harlan Sera-Lab, Loughborough, UK), anti-rat CD11b (clone OX-42, mouse IgG2a; PharMingen, San Diego, CA) antirat CD4 (clone W3/25, mouse IgG1; Serotec), and anti-rat CD8 (clone OX-8, mouse IgG1; Serotec). The second antibody step was performed with Cy3-, Cy2-, or biotin-conjugated donkey anti-goat, donkey antimouse, donkey anti-rabbit, or mouse anti-biotin antisera, respectively (Jackson ImmunoResearch, West Grove, PA). Biotin-labeled secondary antisera were visualized with Cy3-conjugated streptavidin (Jackson ImmunoResearch). The specificity of the immunostainings was tested in control slides by omission of the primary antibody, incubation with preimmune serum (polyclonal antibodies), or incubation with unrelated isotype-matched antibody controls (monoclonal antibodies). Measurements of the immunofluorescence labeling for MHC class II, GFAP, and OX-42 were conducted using a computer-based image analysis system (Lundberg et al., 2001). Measurements were recorded blindly on coded slides, with identical computer and camera settings for all sections. Each reading was taken from a $0.24 \times 0.38 \mathrm{~mm}$ rectangle placed in the ventrolateral part of the ventral horn with a total of 10 different sections 

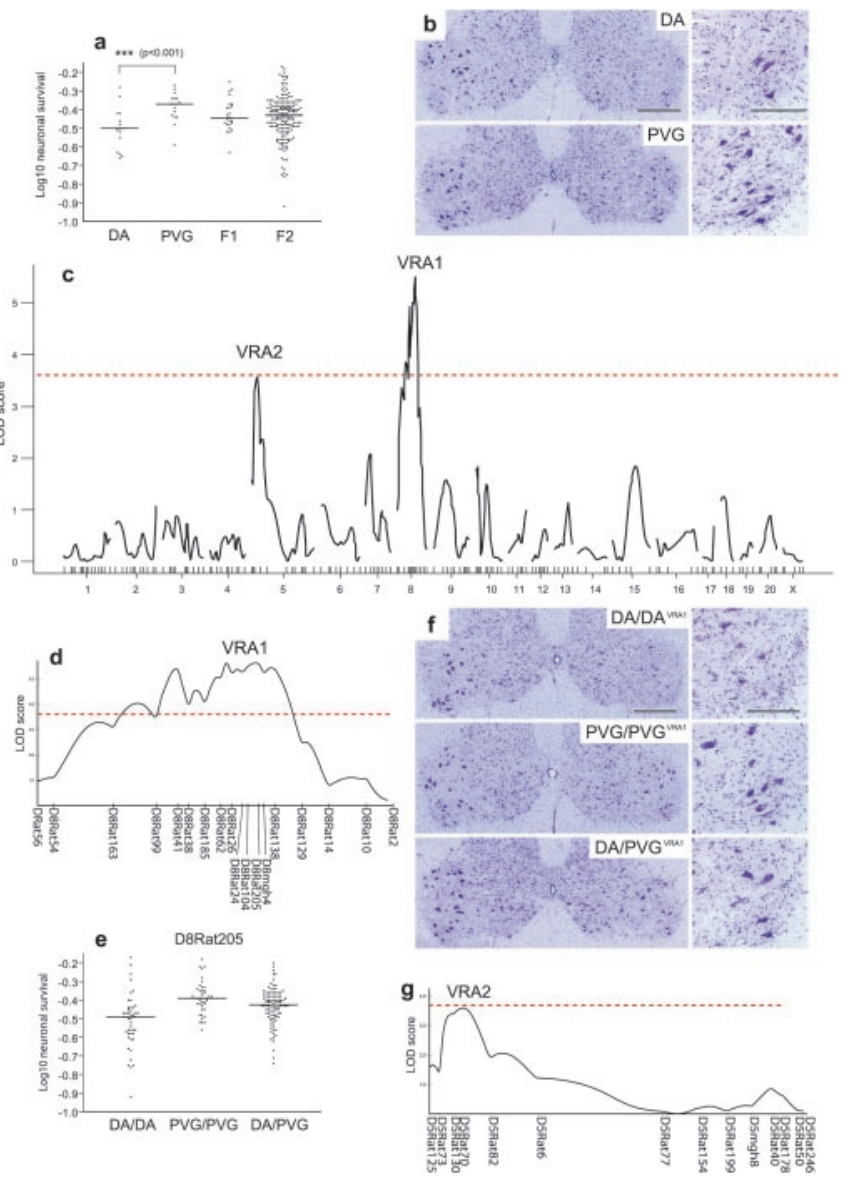

Figure 2. Genetic regulation of nerve injury-induced neurodegeneration. $a$, Relative motoneuron numbers (ratio between lesioned and contralateral sides; base 10 logarithm) in DA, PVG, F1, and F2 populations, with the median indicated. $b$, Micrographs of cresyl violet counterstained spinal cord sections demonstrating increased loss of motoneurons in the DA strain compared with PVG. Scale bar, $0.5 \mathrm{~mm}$. Higher magnification micrographs of the lesioned side of the cord are shown to the right. Scale bar, $0.2 \mathrm{~mm}$. c, Genome-wide LOD score plot for linkage to neurodegeneration in the $\mathrm{F} 2$ population. Threshold for significant linkage at $95 \% \mathrm{Cl}$ (dashed line) and the location of VRA1 and VRA2 are given. $d$, LOD score plot of the VRA1 QTL on rat chromosome 8. Dashed line indicates threshold for significant linkage at $95 \% \mathrm{Cl}$. e, Survival of motoneurons (base 10 logarithm) in the F2 population stratified for genotype at the max marker of VRA1 (D8Rat205), demonstrating reduced survival in rats homozygous for the DA allele. Lines indicate the median. $f$, Micrographs of cresyl violet counterstained sections from representative animals homozygous for the DA allele (DA/DA), homozygous for the PVG allele (PVG/PVG), and heterozygous (DA/PVG) in VRA1(D8Rat205). Scale bar, $0.5 \mathrm{~mm}$. Higher magnification micrographs of the lesioned side are shown to the right. Scale bar, $0.2 \mathrm{~mm} . g$, LOD score plot for VRA2 QTL at the centromeric end of chromosome 5 in the F2 population. Dashed line indicates threshold for significant linkage at $95 \% \mathrm{Cl}$.

analyzed from each animal. Micrographs were recorded on a Zeiss Axioskop microscope system and processed in Adobe Photoshop 7.0.

Genotyping. Genomic DNA was extracted from rat-tail tips using a standard protocol (Laird et al., 1991). PCR primers for polymorphic simple sequence length polymorphisms (SSLPs) were selected from available Internet databases [Rat Genome Database (http://rgd.mcw. edu) or Center for Genomic Research, Whitehead Institute/MIT (http:// www-genome.wi.mit.edu/rat/public/)]. The primers were purchased from GENSET (Paris, France). One primer in each pair was labeled with $\left[\mathrm{g}-{ }^{33} \mathrm{P}\right]$ ATP (PerkinElmer, Boston, MA), genomic DNA was amplified with a standard PCR protocol, and the amplified fragments where separated on $6 \%$ polyacrylamide gels. Genotypes were recorded manually from autoradiographic films independently by two investigators. DNA from DA and PVG rats were included in for every marker to verify expected polymorphisms between the two alleles. The genetic map was created using MAPMAKER/EXP 3.0b software (Lander et al., 1987). A total set of 177 SSLPs were analyzed, and 79\% of the genome was covered within a marker distance of 10 centimorgan $(\mathrm{cM})$.

Linkage analysis and statistics. Linkage analysis was performed using the MAPMAKER/QTL (Lander and Botstein, 1989) and R/qtl (Broman et al., 2003) computer programs. Phenotype data for neuronal survival and MHC class II expression were subjected to log (base 10) transformation to obtain more symmetric distributions. Data set specific genome-wide significance thresholds, and genome-scan-adjusted $p$ values were calculated by permutation tests (Churchill and Doerge, 1994) using 10,000 permutation replicates. The estimated $95 \%$ genome-wide logarithm of odds (LOD) threshold for neuronal degeneration was $\mathrm{LOD}=3.69, \mathrm{CD}^{+}$cell numbers $\mathrm{LOD}=3.75$, MHC class II expression LOD $=4.24$. A LOD score drop of 1.5 was used to define QTL intervals. Significance levels for phenotypic differences between the parental strains were calculated with two-sided Student's $t$ test or Mann-Whitney rank sum test (neuronal survival) using GraphPad (San Diego, CA) Prism 3.0. The statistical significance of the correlations between phenotypes was assessed with permutations tests, using 10,000 permutation replicates.

Genomics. Genomic data, e.g., physical correlate of genetically mapped QTL intervals and identification of syntenic regions in mouse and human, was received from Ensembl (http://www.ensembl.org/), NCBI (http://www. ncbi.nlm.nih.gov/), and Rat Genome Database.

\section{Results}

\section{Neurodegeneration}

Animals from the parental strains, F1 and F2 generations were subjected to unilateral avulsion of the left L3-L5 ventral roots under standardized conditions at an age of 6-8 weeks with a postoperative survival time of $14 \mathrm{~d}$. Counting of motoneurons in the lateral motor nuclei in the L4 spinal cord segment revealed a significant difference in relative numbers of remaining cells between the parental strains, with $36 \%$ increased survival in the PVG rat compared with DA (Figs. 1,2). As a measure of ongoing neurodegeneration, clusters of $\mathrm{CD} 11 \mathrm{~b} / \mathrm{c}^{+}$microglia in the lateral motor nuclei were determined (Petitto et al., 2003). The number of clusters was significantly higher in parental DA rats compared with PVG (mean number per section 1.00 vs 0.39 ; $p$ value $=$ 0.0011), which provide additional support for a more pronounced neurodegeneration in the DA strain. Genome-wide screening with polymorphic microsatellite markers and linkage analysis in the entire F2 population revealed one genome significant locus on chromosome 8 (VRA1), near marker D8R205, attaining a logarithm of odds (LOD) score of 5.5 for linkage to neurodegeneration (Fig. 2). Permutation test analysis, with adjustment for genome scan, gave a $p$ value of 0.002 . The $1.5 \mathrm{LOD}$ score drop supported QTL interval was $\sim 37 \mathrm{cM}$. The approximate physical genomic size of this locus is 50 mega bases (Mb). VRA1 is syntenic to a region on mouse chromosome 9 (MMU9 B-E3.2) and to human 11q22.3-23.3, 15q21.3-25.2, 6p12.1, and 6q14.1-14.3. In addition, a second locus on chromosome 5 (VRA2), near marker D5R70, displayed suggestive linkage (LOD 3.6; $p=0.066$ ) to cell death (Fig. 2).

\section{T lymphocyte infiltration}

Assessment of numbers of $\mathrm{CD}^{+}{ }^{+}$-positive cells was used as a measure of T cell infiltration. Only a few cells were detected per section, but they were inevitably located to the motor nuclei of the ventral horn of the lesioned side (Fig. 3). Cell counts revealed a clear strain-dependent difference in parental strains, with sevenfold higher cell numbers in DA rats. Two loci with impact on lymphocyte numbers were identified on chromosome 5 (Fig. 3). The first locus displaying significant linkage (LOD 4.6; $p=0.011$ ) was at precisely the same location as the VRA2 QTL, and these loci will therefore henceforth collectively be denoted VRA2. The 1.5 
LOD score QTL interval for VRA2 was $~ 29$ cM. Syntenic regions are parts of mouse chromosome 1 and 4 and human $8 \mathrm{q} 12$, 8q22.1, and 1p35.2-36.11. The second locus (VRA3) displayed suggestive linkage (LOD $3.4 ; p=0.092$ ) to $\mathrm{T}$ cell accumulation and was located at the telomeric end of chromosome 5. A more detailed analysis of infiltrating cells was performed in DA parental rats, with double labeling for CD3 (pan T cell marker) and CD4 (T helper cells), CD8 (cytotoxic T cells) or NKR-P1 (natural killer cells; NK cells), respectively. Approximately $60 \%$ of the $\mathrm{CD}^{+}{ }^{+}$cells were also CD ${ }^{+}, 40 \%$ were $\mathrm{CD} 3{ }^{+} \mathrm{CD} 4{ }^{+}$, and no NKR-P1 ${ }^{+} \mathrm{CD} 3{ }^{+}$ cells could be detected. However, the presence of small numbers of NK cells was suggested by occasional NKR-P1 ${ }^{+} \mathrm{CD} 3{ }^{-}$cells. A weak significant correlation $(r=0.21 ; p=$ 0.007 ) was evident in the $\mathrm{F} 2$ generation between the number of infiltrating $\mathrm{CD}^{+}$ cells and the degree of neurodegeneration in individual rats.

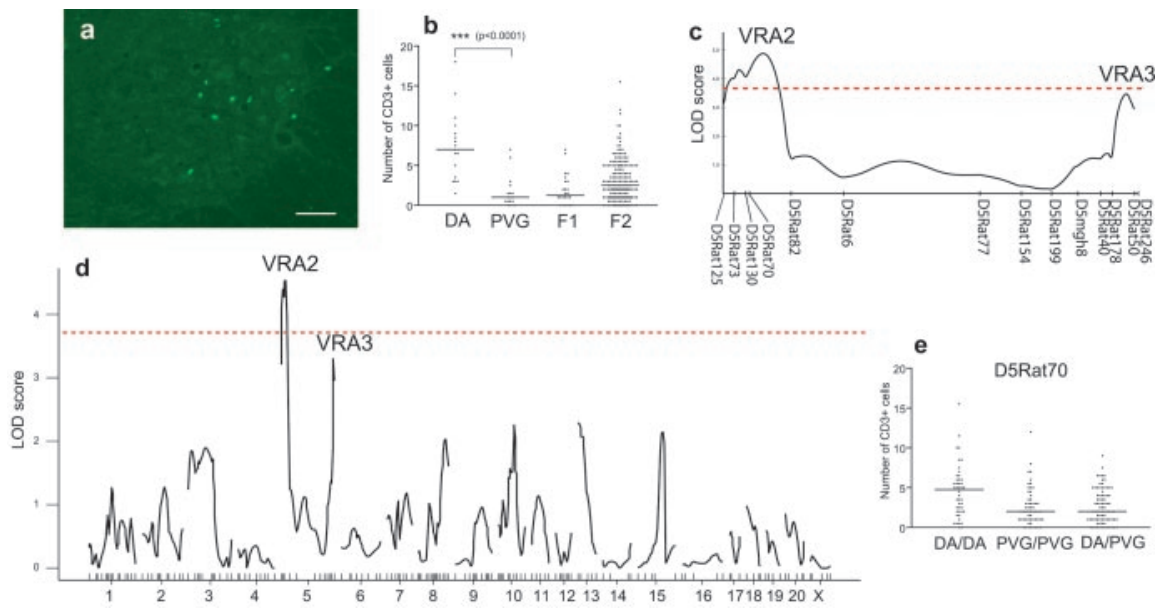

Figure 3. Genetic regulation of $\mathrm{T}$ cell infiltration. $a$, Micrograph showing infiltrating $\mathrm{CD} 3^{+}$cells in the ventral horn of a DA rat. Scale bar, $0.2 \mathrm{~mm} . b$, The number of $\mathrm{CD}^{+}{ }^{+}$cells in the ventral horn after VRA demonstrates a strain-dependent influence, with higher cell counts in DA rats. Lines indicate the median. No clear gene dosage effect is evident in the F1 population. $c$, LOD score plot of the VRA2 and VRA3 QTLs on chromosome 5. d, Genome-wide LOD score plot for linkage to T cell infiltration in the F2 population. Threshold for significant linkage at $95 \% \mathrm{Cl}$ (dashed line) and the location of VRA2 and VRA3 are indicated.e, $\mathrm{CD}^{+}{ }^{+}$cell numbers in the F2 population stratified for genotype at the max marker of VRA2 (D5Rat70), demonstrating increased cell numbers in animals homozygous for the DA allele.

\section{Glial activation}

Activation of microglia and astrocytes was assessed by labeling for $\mathrm{CD} 1 \mathrm{~b} / \mathrm{c}(\mathrm{OX}-42)$ and glial fibrillary acidic protein (GFAP), respectively (Fig. 1). Both parameters were significantly increased in DA rats compared with PVG rats. However, no significant linkage to discrete gene loci could be demonstrated in the F2 population. The reason for this could be technical or biological, e.g., too polygenic traits, or a combination of both.

\section{MHC class II expression}

MHC class II-positive cells were predominately located to the axotomized motor nuclei and the white matter tracts containing traversing motor axons (Fig. 4). Measurements of the percentage of positively labeled area in the parental strains demonstrated an almost 10-fold greater labeled area in the DA strain. In the F2 population a major influence, with extreme linkage (LOD score 27.4; $p<0.001$ ), on labeling pattern could be mapped to the centromeric part of chromosome 10 with a 1.5 LOD score supported interval of $\sim 4 \mathrm{cM}$ (VRA4) (Fig. 4 ). This locus was responsible for an estimated $56 \%$ of the variation in the phenotype. VRA4 corresponds to the centromeric part of mouse chromosome 16 and human 16p13. The MHC complex itself on chromosome 20 displayed only a weak effect, attaining a LOD score of $2.6(p=0.45)$. Double labeling with glial markers showed that MHC class II in the cord was expressed exclusively by microglia (data not shown). Analysis of the phenotype of individual rats in the F2 generation demonstrated a significant, albeit modest, correlation $(r=0.30 ; p<0.001)$ between the degree of MHC class II expression and numbers of infiltrating $\mathrm{CD} 3{ }^{+}$cells, but not with the degree of nerve cell loss.

\section{Discussion}

The results presented herein to the best of our knowledge represent the first effort of genetic dissection of nerve injury-induced neurodegeneration and inflammation using techniques developed for polygenic diseases. A key finding is that features of the axon reaction are controlled by a low number of discrete positioned gene loci containing genes polymorphic between strains. Conceivably, the polymorphisms of such genes may be evolu- tionary conserved, whereby the allelic variants have been kept to provide some kind of survival benefit on the population level. Such genes may, however, under some circumstances be diseasepromoting. These types of polymorphic genes may therefore be crucial for the regulation of susceptibility to common diseases and of relevance for many individuals within the population, e.g., with high prevalence and low penetrance (Tanzi and Bertram, 2001). This can be illustrated by differences in incidence of late onset or sporadic forms as compared with the much rarer familial cases in several neurodegenerative diseases (Myers and Goate, 2001; Rowland and Shneider, 2001; Nussbaum and Ellis, 2003), as well as the potential sharing of risk alleles between different diseases (Schmitt et al., 1984; Majoor-Krakauer et al., 1994).

Within the loci reported here there are many candidate genes, which can be determined using flanking marker information and the publicly available rat genome map (http://www.ensembl.org/ Rattus_norvegicus/).

The degree of neurodegeneration displayed significant linkage to a region on chromosome 8 (VRA1). Numerous mechanisms have previously been proposed and proven to be involved in the regulation of nerve cell death (Pettmann and Henderson, 1998; Liou et al., 2003; Vila and Przedborski, 2003). The data provided here demonstrate that there exists gene polymorphisms explaining differences in the susceptibility to induced nerve cell death, and the exact definition of these will provide information on which upstream mechanism that may be pathogenetically crucial. Interestingly, VRA1 is partly overlapping with a QTL recently described by us in a genetic mapping of experimental autoimmune encephalomyelitis (EAE), a model for multiple sclerosis (MS) (Becanovic et al., 2003). In the case of EAE however, it is not possible to discriminate between genes regulating the systemic immune response from those regulating target tissue vulnerability. Consistent with a target-specific role, the locus segregated for cumulative score in EAE, a compound measure of neurological dysfunction reflecting disease severity and chronicity, but not with disease incidence or various inflammatory parameters. This suggests that susceptibility to various types of insults of the CNS is regulated by this locus. 

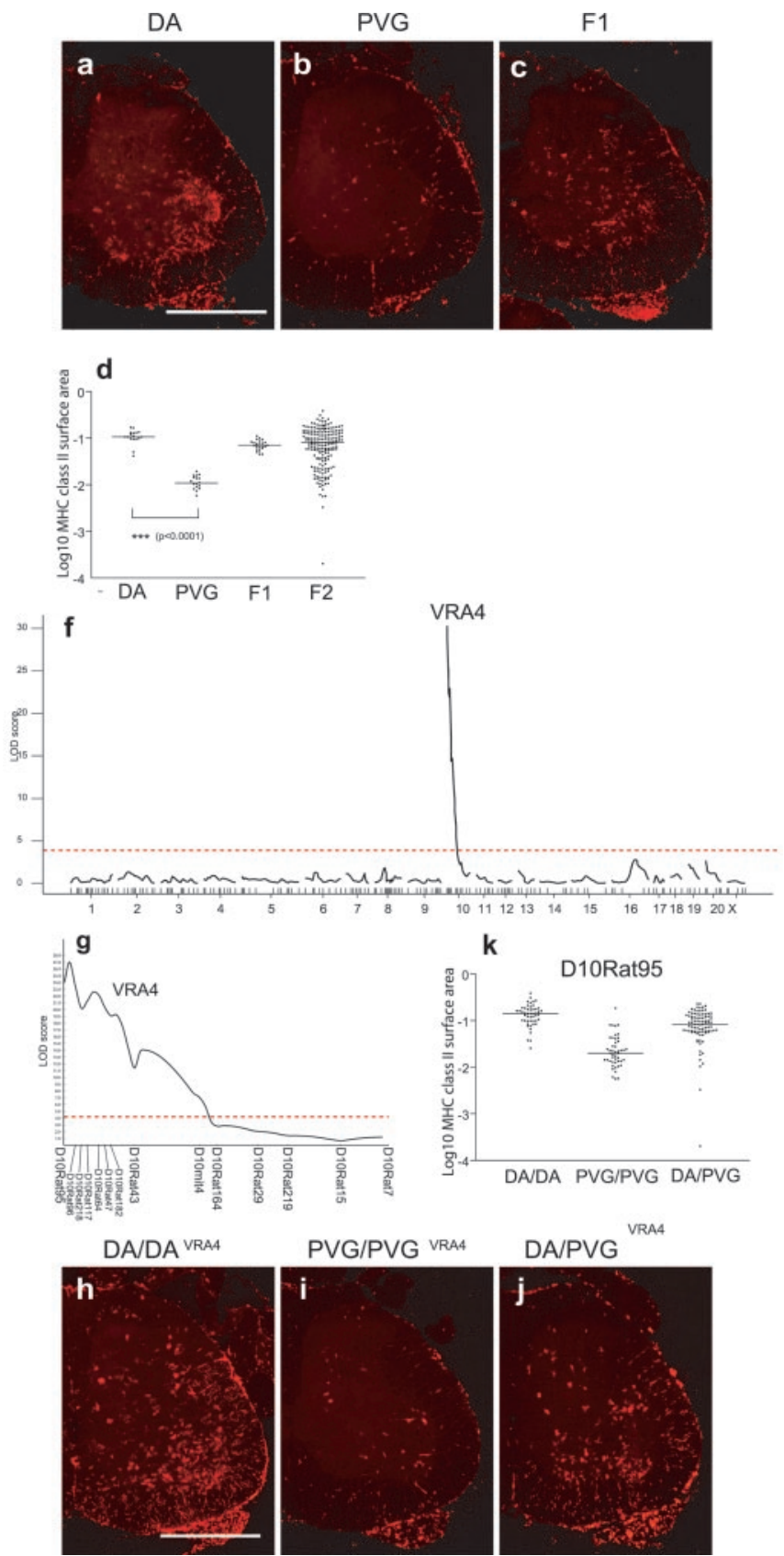

DA/PVG

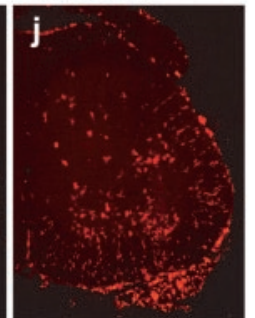

Figure 4. Genetic regulation of MHC class II expression. $a-c$, Micrographs showing MHC class II immunolabeling in the ventral horn of a DA $(a)$, PVG (b), and F1 (c) rat. Scale bar, $1 \mathrm{~mm}$. $d$, MHC class II-labeled surface area (base 10 logarithm) in DA, PVG, F1, and F2 populations, with the median indicated. The 0.99 ( $\log 10)$ difference between DA and PVG corresponds to an almost 10-fold difference in real terms. The intermediate outcome in the F1 population suggests a gene dosage effect. e, Genome-wide LOD score plot for linkage to MHC class II-labeling in the F2 population. Threshold for significant linkage at $95 \% \mathrm{Cl}$ (dashed line) and the location of VRA4 and the MHC complex are indicated. $f$, LOD score plot of the VRA4 QTL on chromosome 10. $g-i$, Micrographs showing immunolabeling for MHC class II in the ventral horn of F2 rats stratified for the max marker of VRA4 (D10Rat95), demonstrating a much more vigorous response in rats homozygous for the DA allele $(g)$ compared with PVG homozygous $(h)$ and heterozygous ( $i$ ) animals. Scale bar, $1 \mathrm{~mm}$. j, MHC class Il-labeled surface area in F2 rats stratified for haplotype at the max marker of VRA4 (D10Rat95).

In neurodegenerative conditions the presence of $\mathrm{T}$ cells in the CNS has been described (Itagaki et al., 1988; Kawamata et al., 1992; Engelhardt et al., 1993; Raivich et al., 1998; Togo et al., 2002), although of unclear significance so far. However, in pri- mary inflammatory diseases of the CNS such as EAE and neuroinfections, infiltration of T cells into the CNS is known to be of prime importance. Hypothesis-driven research has described a series of important fundaments in this process, such as the requirement of peripheral preactivation of the $\mathrm{T}$ cells (Wekerle et al., 1986; Hickey et al., 1991), expression of certain adhesion molecules (Yednock et al., 1992), as well as chemokines and their receptors (Huang et al., 2000; Gerard and Rollins, 2001; Proudfoot, 2002). However, we are not aware of any previous studies on gene polymorphisms regulating the tendency for $\mathrm{T}$ cell influx into the CNS. If present, they may constitute inter-individually different bottlenecks in the regulation of CNS inflammation in general. Here we found that this fundamental process is regulated by two different loci linked to the number of infiltrating CD3 ${ }^{+} \mathrm{T}$ cells, VRA2 and VRA3, both on chromosome 5. A QTL closely adjacent to VRA2 displaying suggestive linkage to onset of EAE has been described (Bergsteinsdottir et al., 2000), implicating the importance of this locus in CNS inflammation. Interestingly VRA2 also displayed suggestive linkage to nerve cell loss in the genome scan presented here. The adaptive arm of the immune system has recently been proposed to exert a neuroprotective role after mechanical nerve injuries (Moalem et al., 1999; Hammarberg et al., 2000), but on the other hand cytotoxic T cells have been suggested to be involved in the killing of MHC class I-expressing neurons in neurodegenerative diseases (Neumann et al., 2002). DA alleles in the VRA2 locus confer both increased neurodegeneration and $\mathrm{T}$ cell accumulation, suggesting an association between these phenotypes. However, the overall correlation in the F2 material was relatively weak, and VRA1 and VRA3 also demonstrate independent genetic regulation of the two processes.

The presence of antigen-presenting cells (APCs) in the target organ is vital for propagating inflammatory reactions. Traditionally CNS tissue has been regarded as an organ with very poor APC capabilities. However, it is now clear that microglia can act as APCs, at least with regard to the reactivation of $\mathrm{T}$ cells primed in the periphery (Aloisi et al., 2000). Local intra-CNS reactivation of autoreactive $T$ cells after recognition of cognate autoantigen presented by class II molecules is pivotal in the pathogenesis of EAE (Flugel et al., 2001). Very early studies with anti-MHC class II molecule blocking antibodies reversed EAE (Steinman et al., 1981). In addition, recent studies suggest that statins may act beneficially in EAE by reducing MHC class II expression (Youssef et al., 2002). Levels of MHC II and the type of costimulatory activation that $\mathrm{CD} 4{ }^{+} \mathrm{T}$ cells encounter are extremely important because these dictate the subsequent response with regard to Th1/2 bias and activation-anergy status, with important consequences for the functional outcome of an immune response (Baumgart et al., 1998). We are here able to demonstrate the presence of profound functional heterogeneity in the control of MHC class II expression on microglia, where genetic mapping reveals extreme linkage to a single locus on chromosome 10 (VRA4). Notably, no significant linkage to the MHC complex itself was detected. VRA4 colocalizes with a suggestive QTL identified in rat collagen-induced arthritis (Furuya et al., 2000) and in a panel of inbred rat strains the degree of MHC class II expression after VRA correlates with susceptibility to EAE (Lundberg et al., 2001), suggesting that VRA4 could be of importance for the regulation of susceptibility to autoimmune disease. We speculate that our observations gives a basis for studying whether differences in the susceptibility to both primary inflammatory and noninflammatory disease, in which class II expression is pre- 
sumed to be important, can depend on inherited differences in the polymorphic genes in the VRA4 QTL.

Further exploration of the QTLs identified in this F2 study are now ongoing in our laboratory using an advanced intercross line (Darvasi and Soller, 1995; Xiong and Guo, 1997) that allows for mapping of regulatory genes down to a resolution of 1-15 genes. In parallel, reciprocal congenization will produce strains that enable testing in autoimmune and neurodegenerative disease models. It will be of interest to compare differentially expressed genes as obtained in global gene expression experiments with the genes contained in the QTLs defined here. Positional identification of responsible genes and the use of comparative genomics may increase our understanding of the regulation of genetic susceptibility for a range of neurological diseases, including nerve trauma, multiple sclerosis, and cerebrovascular and neurodegenerative diseases.

\section{References}

Aloisi F, Ria F, Adorini L (2000) Regulation of T-cell responses by CNS antigen-presenting cells: different roles for microglia and astrocytes. Immunol Today 21:141-147.

Baumgart M, Moos V, Schuhbauer D, Muller B (1998) Differential expression of major histocompatibility complex class II genes on murine macrophages associated with $\mathrm{T}$ cell cytokine profile and protective/suppressive effects. Proc Natl Acad Sci USA 95:6936-6940.

Becanovic K, Wallstrom E, Kornek B, Glaser A, Broman KW, Dahlman I, Olofsson P, Holmdahl R, Luthman H, Lassmann H, Olsson T (2003) New loci regulating rat myelin oligodendrocyte glycoprotein-induced experimental autoimmune encephalomyelitis. J Immunol 170:1062-1069.

Bergsteinsdottir K, Yang HT, Pettersson U, Holmdahl R (2000) Evidence for common autoimmune disease genes controlling onset, severity, and chronicity based on experimental models for multiple sclerosis and rheumatoid arthritis. J Immunol 164:1564-1568.

Broman KW, Wu H, Sen S, Churchill GA (2003) R/qtl: QTL mapping in experimental crosses. Bioinformatics 19:889-890.

Churchill GA, Doerge RW (1994) Empirical threshold values for quantitative trait mapping. Genetics 138:963-971.

Cleveland DW, Rothstein JD (2001) From Charcot to Lou Gehrig: deciphering selective motor neuron death in ALS. Nat Rev Neurosci 2:806-819.

Darvasi A, Soller M (1995) Advanced intercross lines, an experimental population for fine genetic mapping. Genetics 141:1199-1207.

DeStefano AL, Golbe LI, Mark MH, Lazzarini AM, Maher NE, Saint-Hilaire M, Feldman RG, Guttman M, Watts RL, Suchowersky O, Lafontaine AL, Labelle N, Lew MF, Waters CH, Growdon JH, Singer C, Currie LJ, Wooten GF, Vieregge P, Pramstaller PP, et al. (2001) Genome-wide scan for Parkinson's disease: the GenePD Study. Neurology 57:1124-1126.

Engelhardt JI, Tajti J, Appel SH (1993) Lymphocytic infiltrates in the spinal cord in amyotrophic lateral sclerosis. Arch Neurol 50:30-36.

Flugel A, Berkowicz T, Ritter T, Labeur M, Jenne DE, Li Z, Ellwart JW, Willem M, Lassmann H, Wekerle H (2001) Migratory activity and functional changes of green fluorescent effector cells before and during experimental autoimmune encephalomyelitis. Immunity 14:547-560.

Furuya T, Salstrom JL, McCall-Vining S, Cannon GW, Joe B, Remmers EF, Griffiths MM, Wilder RL (2000) Genetic dissection of a rat model for rheumatoid arthritis: significant gender influences on autosomal modifier loci. Hum Mol Genet 9:2241-2250.

Gerard C, Rollins BJ (2001) Chemokines and disease. Nat Immunol 2:108-115.

Gonzalez-Scarano F, Baltuch G (1999) Microglia as mediators of inflammatory and degenerative diseases. Annu Rev Neurosci 22:219-240.

Griffiths MM, Encinas JA, Remmers EF, Kuchroo VK, Wilder RL (1999) Mapping autoimmunity genes. Curr Opin Immunol 11:689-700.

Guillery RW, Herrup K (1997) Quantification without pontification: choosing a method for counting objects in sectioned tissues. J Comp Neurol 386:2-7.

Hammarberg H, Lidman O, Lundberg C, Eltayeb SY, Gielen AW, Muhallab S, Svenningsson A, Linda H, van Der Meide PH, Cullheim S, Olsson T, Piehl F (2000) Neuroprotection by encephalomyelitis: rescue of mechanically injured neurons and neurotrophin production by CNS-infiltrating $\mathrm{T}$ and natural killer cells. J Neurosci 20:5283-5291.

Hickey WF, Hsu BL, Kimura H (1991) T-lymphocyte entry into the central nervous system. J Neurosci Res 28:254-260.

Hicks AA, Petursson H, Jonsson T, Stefansson H, Johannsdottir HS, Sainz J, Frigge ML, Kong A, Gulcher JR, Stefansson K, Sveinbjornsdottir S (2002) A susceptibility gene for late-onset idiopathic Parkinson's disease. Ann Neurol 52:549-555.

Hu J, Fink D, Mata M (2002) Microarray analysis suggests the involvement of proteasomes, lysosomes, and matrix metalloproteinases in the response of motor neurons to root avulsion. Eur J Neurosci 16:1409-1416. Huang D, Han Y, Rani MR, Glabinski A, Trebst C, Sorensen T, Tani M, Wang J, Chien P, O'Bryan S, Bielecki B, Zhou ZL, Majumder S, Ransohoff RM (2000) Chemokines and chemokine receptors in inflammation of the nervous system: manifold roles and exquisite regulation. Immunol Rev 177:52-67.

Itagaki S, McGeer PL, Akiyama H (1988) Presence of T-cytotoxic suppressor and leucocyte common antigen positive cells in Alzheimer's disease brain tissue. Neurosci Lett 91:259-264.

Kawamata T, Akiyama H, Yamada T, McGeer PL (1992) Immunologic reactions in amyotrophic lateral sclerosis brain and spinal cord tissue. Am J Pathol 140:691-707.

Kil K, Zang YC, Yang D, Markowski J, Fuoco GS, Vendetti GC, Rivera VM, Zhang JZ (1999) T cell responses to myelin basic protein in patients with spinal cord injury and multiple sclerosis. J Neuroimmunol 98:201-207.

Koliatsos VE, Price WL, Pardo CA, Price DL (1994) Ventral root avulsion: an experimental model of death of adult motor neurons. J Comp Neurol 342:35-44.

Kreutzberg GW, Graeber MB, Streit WJ (1989) Neuron-glial relationship during regeneration of motorneurons. Metab Brain Dis 4:81-85.

Laird PW, Zijderveld A, Linders K, Rudnicki MA, Jaenisch R, Berns A (1991) Simplified mammalian DNA isolation procedure. Nucleic Acids Res 19:4293.

Lander ES, Botstein D (1989) Mapping Mendelian factors underlying quantitative traits using RFLP linkage maps. Genetics 121:185-199.

Lander ES, Green P, Abrahamson J, Barlow A, Daly MJ, Lincoln SE, Newburg L (1987) MAPMAKER: an interactive computer package for constructing primary genetic linkage maps of experimental and natural populations. Genomics 1:174-181.

Lieberman AR (1971) The axon reaction: a review of the principal features of perikaryal responses to axon injury. Int Rev Neurobiol 14:49-124.

Liou AK, Clark RS, Henshall DC, Yin XM, Chen J (2003) To die or not to die for neurons in ischemia, traumatic brain injury and epilepsy: a review on the stress-activated signaling pathways and apoptotic pathways. Prog Neurobiol 69:103-142.

Lundberg C, Lidman O, Holmdahl R, Olsson T, Piehl F (2001) Neurodegeneration and glial activation patterns after mechanical nerve injury are differentially regulated by non-MHC genes in congenic inbred rat strains. J Comp Neurol 431:75-87.

Maehlen J, Olsson T, Zachau A, Klareskog L, Kristensson K (1989) Local enhancement of major histocompatibility complex (MHC) class I and II expression and cell infiltration in experimental allergic encephalomyelitis around axotomized motor neurons. J Neuroimmunol 23:125-132.

Majoor-Krakauer D, Ottman R, Johnson WG, Rowland LP (1994) Familial aggregation of amyotrophic lateral sclerosis, dementia, and Parkinson's disease: evidence of shared genetic susceptibility. Neurology 44:1872-1877.

McGeer PL, Itagaki S, Boyes BE, McGeer EG (1988) Reactive microglia are positive for HLA-DR in the substantia nigra of Parkinson's and Alzheimer's disease brains. Neurology 38:1285-1291.

McIntire JJ, Umetsu SE, Akbari O, Potter M, Kuchroo VK, Barsh GS, Freeman GJ, Umetsu DT, DeKruyff RH (2001) Identification of Tapr (an airway hyperreactivity regulatory locus) and the linked Tim gene family. Nat Immunol 2:1109-1116.

Moalem G, Leibowitz-Amit R, Yoles E, Mor F, Cohen I, Schwartz M (1999) Autoimmune $\mathrm{T}$ cells protect neurons from secondary degeneration after central nervous system axotomy. Nat Med 5:49-55.

Myers A, Wavrant De-Vrieze F, Holmans P, Hamshere M, Crook R, Compton D, Marshall H, Meyer D, Shears S, Booth J, Ramic D, Knowles H, Morris JC, Williams N, Norton N, Abraham R, Kehoe P, Williams H, Rudrasingham V, Rice F, Giles P, Tunstall N, Jones L, Lovestone S, Wil- 
liams J, Owen MJ, Hardy J, Goate A (2002) Full genome screen for Alzheimer disease: stage II analysis. Am J Med Genet 114:235-244.

Myers AJ, Goate AM (2001) The genetics of late-onset Alzheimer's disease. Curr Opin Neurol 14:433-440.

Neumann H, Medana IM, Bauer J, Lassmann H (2002) Cytotoxic T lymphocytes in autoimmune and degenerative CNS diseases. Trends Neurosci 25:313-319.

Nissl F (1892) Über die Veranderungen der Ganlienzellen am Facialiskern des Kaninchens nach Ausreissung der Nerven. Allg Z Psychiatr 48:197-198.

Nussbaum RL, Ellis CE (2003) Alzheimer's disease and Parkinson's disease. N Engl J Med 348:1356-1364.

Olofsson P, Holmberg J, Tordsson J, Lu S, Akerstrom B, Holmdahl R (2003) Positional identification of $\mathrm{Ncfl}$ as a gene that regulates arthritis severity in rats. Nat Genet 33:25-32.

Olsson T, Kristensson K, Ljungdahl A, Maehlen J, Holmdahl R, Klareskog L (1989) Gamma-interferon-like immunoreactivity in axotomized rat motor neurons. J Neurosci 9:3870-3875.

Petitto JM, Huang Z, Lo J, Streit WJ (2003) IL-2 gene knockout affects T lymphocyte trafficking and the microglial response to regenerating facial motor neurons. J Neuroimmunol 134:95-103.

Pettmann B, Henderson CE (1998) Neuronal cell death. Neuron 20:633-647.

Piehl F, Lundberg C, Khademi M, Bucht A, Dahlman I, Lorentzen J, Olsson T (1999) Non-MHC gene regulation of nerve root injury-induced spinal cord inflammation and neuron death. J Neuroimmunol 101:87-97.

Proudfoot AE (2002) Chemokine receptors: multifaceted therapeutic targets. Nat Rev Immunol 2:106-115.

Raivich G, Jones L, Kloss C, Werner A, H N, Kreutzberg G (1998) Immune surveillance in the injured nervous system: T-lymphocytes invade the axotomized mouse facial motor nucleus and aggregate around sites of neuronal degeneration. J Neurosci 18:5804-5816.

Rowland LP, Shneider NA (2001) Amyotrophic lateral sclerosis. N Engl J Med 344:1688-1700.

Schmitt HP, Emser W, Heimes C (1984) Familial occurrence of amyotrophic lateral sclerosis, parkinsonism, and dementia. Ann Neurol 16:642-648.
Scott WK, Nance MA, Watts RL, Hubble JP, Koller WC, Lyons K, Pahwa R, Stern MB, Colcher A, Hiner BC, Jankovic J, Ondo WG, Allen Jr FH, Goetz CG, Small GW, Masterman D, Mastaglia F, Laing NG, Stajich JM, Slotterbeck B, et al. (2001) Complete genomic screen in Parkinson disease: evidence for multiple genes. JAMA 286:2239-2244.

Steinman L, Rosenbaum JT, Sriram S, McDevitt HO (1981) In vivo effects of antibodies to immune response gene products: prevention of experimental allergic encephalitis. Proc Natl Acad Sci USA 78:7111-7114.

Strittmatter WJ, Weisgraber KH, Huang DY, Dong LM, Salvesen GS, PericakVance M, Schmechel D, Saunders AM, Goldgaber D, Roses AD (1993) Binding of human apolipoprotein $\mathrm{E}$ to synthetic amyloid beta peptide: isoform-specific effects and implications for late-onset Alzheimer disease. Proc Natl Acad Sci USA 90:8098-8102.

Tanzi RE, Bertram L (2001) New frontiers in Alzheimer's disease genetics. Neuron 32:181-184.

Togo T, Akiyama H, Iseki E, Kondo H, Ikeda K, Kato M, Oda T, Tsuchiya K, Kosaka K (2002) Occurrence of T cells in the brain of Alzheimer's disease and other neurological diseases. J Neuroimmunol 124:83-92.

Trapp B, Peterson J, Ransohoff R, Rudick R, Mørk S, Bø L (1998) Axonal transection in the lesions of multiple sclerosis. N Engl J Med 338:278 -285.

Vila M, Przedborski S (2003) Targeting programmed cell death in neurodegenerative diseases. Nat Rev Neurosci 4:365-375.

Wekerle H, Linnington C, Lassmann H, Meyermann R (1986) Cellular immune reactivity within the CNS. Trends Neurosci 9:271-277.

Wyss-Coray T, Mucke L (2002) Inflammation in neurodegenerative disease: a double-edged sword. Neuron 35:419-432.

Xiong M, Guo SW (1997) Fine-scale mapping of quantitative trait loci using historical recombinations. Genetics 145:1201-1218.

Yednock TA, Cannon C, Fritz LC, Sanchez-Madrid F, Steinman L, Karin N (1992) Prevention of experimental autoimmune encephalomyelitis by antibodies against alpha 4 beta 1 integrin. Nature 356:63-66.

Youssef S, Stuve O, Patarroyo JC, Ruiz PJ, Radosevich JL, Hur EM, Bravo M, Mitchell DJ, Sobel RA, Steinman L, Zamvil SS (2002) The HMG-CoA reductase inhibitor, atorvastatin, promotes a Th2 bias and reverses paralysis in central nervous system autoimmune disease. Nature 420:78-84. 